Transactions of the American Fisheries Society, Vol. 128, Num. 3, 1999: pp. 542-548.

http://afs.allenpress.com/perlserv/?request=get-archive

DOI: 10.1577/1548-8659(1999)128<0542:EOEATO >2.0.CO;2

(C) American Fisheries Society 1999 


\title{
Effects of Extenders and Time of Storage before Freezing on Motility and Fertilization of Cryopreserved Muskellunge Spermatozoa
}

\author{
A. Ciereszko \\ School of Natural Resources, The Ohio State University, \\ 210 Kottman Hall, 2021 Coffey Road, Columbus, Ohio 43210, USA and \\ Department of Molecular Andrology, Institute of Animal Reproduction and Food Science, \\ Polish Academy of Sciences, 10-718 Olsztyn-Kortowo, Poland \\ K. DABROWSKI* AND F. LIN \\ School of Natural Resources, The Ohio State University, \\ 210 Kottman Hall, 2021 Coffey Road, Columbus, Ohio 43210, USA

\section{S. A. Christ And G. P. Toth} \\ Ecological Exposure Research Division, National Exposure Research, \\ U.S. Environmental Protection Agency, Cincinnati, Ohio 45268, USA
}

\begin{abstract}
The usefulness of five extenders for cryopreservation of muskellunge semen was studied in fertilization trials and computer-assisted semen analysis (CASA) of postthaw sperm motility. The effect of prefreezing storage time before cryopreservation on success of cryopreservation was also analyzed. A 50\% fertilization rate (compared with fresh semen) of the extender containing $10 \%$ dimethyl sulfoxide (DMSO) in seminalplasma-mimicking medium (SPMM) supplemented by $10 \%$ egg yolk was significantly higher than in extenders consisting of $10 \%$ DMSO, $0.6 \mathrm{M}$ sucrose, and $10 \%$ egg yolk or $20 \%$ glycerol and $0.3 \mathrm{M}$ glucose. Spermatozoa cryopreserved with DMSO-SPMM-egg yolk extender had the highest values of straight-line velocity and linearity of movement. Significantly lower fertilizing ability and curvilinear velocity were found for semen specimens stored on ice for $5 \mathrm{~h}$ before freezing compared with specimens stored for $1 \mathrm{~h}$. Although spermatozoa cryopreserved with extender containing $10 \%$ methanol had only traces of motility or no motility at all after thawing, fertilization trials indicated that their fertilizing ability was preserved. Despite a lack of motility after thawing, these spermatozoa could have been activated by egg components, thus indicating that they could have been motile during fertilization. This possibility suggests that the motility pattern of muskellunge spermatozoa may be influenced during fertilization by egg components.
\end{abstract}

Cryopreservation is now a widely used method for long-term storage of fish semen (for recent reviews see Piironen 1995 and Rana 1995). Components of cryopreservation technology are similar in fish. They include dilution of fresh semen

\footnotetext{
* Corresponding author: dabrowski.1@osu.edu Received August 25, 1997; accepted July 22, 1998
}

in extender containing cryoprotectant, frequent use of dimethyl sulfoxide (DMSO), a short equilibration period, freezing as pellets on dry ice or in vials or straws over liquid nitrogen, storage in liquid nitrogen, and thawing in appropriate solutions and at a specific temperature just before fertilization (Rana 1995). However, a number of distinct protocols have been developed for particular fish due to species-specific requirements for freezing or thawing. For example, spermatozoa of yellow perch Perca flavescens can be frozen with extender containing DMSO but not glycerol ( $\mathrm{Ci}$ ereszko et al. 1993), and spermatozoa of Pacific herring Clupea pallasi, unlike most other species, appear to be best cryopreserved when frozen by direct plunging into liquid nitrogen (Pillai et al. 1994). For this reason, the optimal cryopreservation technique should be determined before the milt of an untested species is introduced for longterm storage.

Computer-assisted sperm motility analysis (CASA) has been recently introduced for the study of fish sperm (Toth et al. 1995; Ciereszko et al. 1996). This method may replace the subjective estimation of sperm motility by light microscope. Subjective estimation lacks sensitivity and is unable to quantify such components of sperm motion as velocity and pattern of movement. Better understanding of sperm movement may lead to identification of those components of the movement that can be used for assessing sperm quality.

In our previous work, we successfully cryopreserved semen of muskellunge Esox masquinongy using a DMSO-sucrose extender (Lin et al. 1996). 
The objectives of this study were to examine the effects of (1) two prefreezing storage times and (2) five different extenders of varying composition on cryopreservation success of muskellunge spermatozoa, as measured by fertilization rate and motility.

\section{Methods}

Muskellunge gametes were collected in April 1995 from fish captured by trap net from Clear Fork Reservoir, Ohio. Semen was obtained by stripping from 16 males as described in Lin et al. 1996. Samples contaminated with urine or blood were discarded. We formed five milt samples, each containing milt pooled from three to four different males. Semen was stored on ice until used. We determined mean sperm concentration $(+\mathrm{SD})$ to be $15.72+1.40 \times 10^{9} / \mathrm{mL}$ and percentage of motile spermatozoa to be $80+14 \%$ for these samples. Sperm concentration was determined by a spectrophotometric method (Ciereszko and Dabrowski 1993; Lin et al. 1996). Eggs were obtained from one female and stored at approximately $10^{\circ} \mathrm{C}$ for $8 \mathrm{~h}$ before fertilization experiments, which does not result in reduction of egg quality (Lin and Dabrowski 1996).

We tested the effects of extender composition and time of chilled storage after semen collection on the fertilization success of cryopreserved spermatozoa and posthaw sperm motility. The first cryopreservation was completed in the field using half of the semen from the five pooled milt samples, stored on ice, within $1 \mathrm{~h}$ after collection. The remaining half of the semen was stored on ice for $5 \mathrm{~h}$ and cryopreserved by the same procedure in the aquaculture facility of the Ohio State University School of Natural Resources, Columbus, Ohio. Sperm fertilizing ability was tested on the day of cryopreservation. Due to a shortage of eggs, only the first four extenders listed below were used for fertilization studies; all five extenders were employed in CASA analysis. The same samples of frozen sperm were tested 5 months later for sperm motility measurements by CASA. Motility characteristics were tested for sperm frozen in all five extenders. All five semen pools were employed in this experiment. However, additional manual estimation with a light microscope of percent motile spermatozoa was performed 12 months later using specimens stored in liquid nitrogen for samples cryopreserved in methanol-Ringer extender due to lack of sperm motility measured by CASA.

Due to a lack of clear criteria for selecting extenders for semen cryopreservation of a new fish species, we arbitrarily decided to test two extenders that were used previously for muskellunge and northern pike Esox lucius and three other extenders that were successfully used with other species. All extenders were prepared in double-distilled water. The following five extenders were used: (1) DMSO-sucrose-yolk, which consisted of $10 \%$ DMSO and 0.6 M sucrose supplemented with $10 \%$ egg yolk (Holtz 1993; Ciereszko and Dabrowski 1996; Lin et al. 1996); (2) DMSO-SPMM-yolk, which consisted of $10 \%$ DMSO in seminal-plasmamimicking medium (SPMM) (Erdhal and Graham 1987) supplemented with $10 \%$ egg yolk, as described by Babiak et al. (1995); (3) glycerol-glucose, which consisted of $20 \%$ glycerol and $0.3 \mathrm{M}$ glucose (Piironen and Hyvärinen 1983); (4) methanol-Ringer, which was $10 \%$ methanol in modified fish Ringer solution (Rana and McAndrew 1989); and (5) DMSO-sucrose-potassium bicarbonateGSH, which was one part DMSO (12.5\% final concentration) mixed with seven parts of medium containing $125 \mathrm{mM}$ sucrose, $100 \mathrm{mM}$ potassium bicarbonate, and $6.5 \mathrm{mM}$ reduced glutathione (GSH) (Mounib 1978; Ciereszko et al. 1993).

Semen and extenders were stored separately on ice for either 1 or $5 \mathrm{~h}$. After respective storage times, four parts of extender were combined and than gradually added within $15 \mathrm{~s}$ to one part of semen. Temperature of extended semen before freezing was not monitored. Extended semen was then immediately pelleted into 2-mm depressions on dry ice $\left(-79^{\circ} \mathrm{C}\right)$ with the use of an Eppendorf repeator pipet (Brinkman, VWR Scientific, Cleveland, Ohio), as described by Ciereszko et al. (1993). After $3-5 \mathrm{~min}$, the pellets $(0.1 \mathrm{~mL})$ were transferred to liquid nitrogen $\left(-196^{\circ} \mathrm{C}\right)$.

All fertilization trials were performed (in duplicate) on the day of cryopreservation, after semen had been stored in liquid nitrogen for $1-6 \mathrm{~h}$. Two pellets $(200 \mu \mathrm{L})$ of cryopreserved semen were thawed $(5-7 \mathrm{~s})$ at room temperature in $4 \mathrm{~mL}$ of 30 $\mathrm{mM}$ tris- $\mathrm{HCl}$ buffer, supplemented with $75 \mathrm{mM}$ $\mathrm{NaCl}(\mathrm{pH}, 8.0)$. The suspension of thawed semen was poured over about $3 \mathrm{~g}$ of egg mass $(314+26$ eggs) in a $100-\mathrm{mL}$ plastic beaker. Fresh undiluted semen $(40 \mu \mathrm{L})$, stored $5 \mathrm{~h}$ on ice and from the same pools of semen that were used for cryopreservation, was used as a control. The average sperm: egg ratio was $2.00+0.18 \times 10^{6}$. Approximately $2 \mathrm{~min}$ after fertilization, dechlorinated water was added. After washing (four times with $100 \mathrm{~mL}$ of dechlorinated water each time), eggs were transferred to the incubation apparatus, a miniature version of Weiss incubator jars with a 
constant water flow (Bardega and Luczynski 1990). Eggs were incubated at $12^{\circ} \mathrm{C}$ with a constant water flow. We recorded survival rate three times after fertilization: at $4 \mathrm{~d}, 12 \mathrm{~d}$ (eyed stage), and $17 \mathrm{~d}$ (after hatching).

Samples stored for 5 months in liquid nitrogen were used for CASA analysis. Motility analysis was performed at room temperature $\left(22^{\circ} \mathrm{C}\right)$. Semen was thawed and activated under the same conditions as in the fertilization trials, using $30 \mathrm{mM}$ tris- $\mathrm{HCl}$ buffer containing $75 \mathrm{mM} \mathrm{NaCl}(\mathrm{pH}, 8.0)$. This medium caused sperm activation. Thawing of semen for both fertilization and motility studies was performed by the same person to minimize possible variability due to thawing technique. One pellet was used to insure optimal sperm concentration for CASA analysis. Thawing time was approximately 5-7 s. Two replications were filmed 15-20 s after beginning thawing. Activated sperm suspensions were loaded into a 20- $\mu \mathrm{m}$ Microcell (Conception Technologies, La Jolla, California). Several visual fields of an Olympus BH2 microscope of each sperm sample were videotaped with a 200-Hz video camera (NAC, Japan) and highspeed VCR (Motion Analysis Corp., Santa Rosa, California). Videotapes were subsequently analyzed using the CellTrak/S (version 3.2; Motion Analysis Corp.) computer-assisted sperm analysis system. A video digitizing rate of 200 frames/s was used to gather data.

Spermatozoa were tracked for 25 consecutive frames (out of 49 collected) for calculating kinematics and for determining motility. Eight to 10 videotape fields (recorded 15-20 s after thawing, verified by a time and date signal record on the videotape) were included at each analysis time point for activation condition and repetition. The percentage of motile spermatozoa, curvilinear velocity (VCL), straight line velocity (VSL), linearity (LIN), and amplitude of lateral head displacement (ALH) were then determined. These motility characteristics were described by Owen and Katz (1993) and Toth et al. (1997). The VCL and VSL are defined as the time-average velocity of sperm head along its actual trajectory or along a straight line from its first detection point to its line detection point, respectively. The LIN indicates relationship between VSL and VCL. The ALH is the amplitude of lateral head displacement, and shows displacement of the actual track from a calculated average path.

Sperm motility estimates of sperm frozen in methanol-Ringer extender were subjectively assessed by light microscope under $200 \times$ magnifi- cation because little or no motility was observed using CASA. No cover glass was used. Samples were thawed and activated under the same conditions as CASA. Then the same subjective assessment was performed with use of "egg water" thawing medium. Egg water consisted of the same tris- $\mathrm{HCl}$ buffer used in fertility and motility trials, but incubated with muskellunge eggs obtained from one female (four parts of buffer to three parts of eggs, weight to weight) for $5 \mathrm{~min}$. Following this, eggs were removed by filtration through a fine net. Because the eggs were sticky, no attempt to separate ovarian fluid was made. Eight different semen samples were used in the first assessment to observe motility in the sperm drop. Five different paired samples (with $30 \mathrm{mM}$ tris- $\mathrm{HCl}$ containing $75 \mathrm{mM} \mathrm{NaCl}(\mathrm{pH}, 8.0)$ were used in the second experiment testing the effect of egg water on sperm motility.

We analyzed sperm motility and fertilizing ability data under a two-way analyis of variance with a repeated-measures design. The independent variables were extenders and time of semen storage before freezing. We used the general linear models procedure in the SAS data analysis package (SAS Institute 1989). The percentage data were subjected to arcsine transformation before calculations to normalize these data. Effect of egg water on the percentage of motile sperm cryopreserved in methanol-Ringer extender was evaluated by Mann-Whitney $U$-test. Differences were considered significant at $P<0.05$.

\section{Results}

At $4 \mathrm{~d}$ after fertilization, we found $88.4+2.4 \%$ live embryos in the control group when fresh semen was used. We recorded $8 \%$ further embryo loss at eyed stage $(81.3+6.4 \%)$ for this group and less than $1 \%$ further loss before hatching (80.6 $+6.5 \%)$.

We observed a high variability of fertilizing capacity when using semen cryopreserved in the methanol-Ringer extender. For example, survival at eyed stage of semen stored for $1 \mathrm{~h}$ ranged from $0 \%$ to $67.9 \%(29.7+28.3)$. For this reason, we did not include data for this extender in statistical comparisons. All three remaining extenders preserved sperm fertilizing ability (Table 1 ). The best survival after $4 \mathrm{~d}$ of egg incubation $(50.1 \%$ and $44.0 \%$ for semen stored for $1 \mathrm{~h}$ and $5 \mathrm{~h}$, respectively) was found when DMSO-SPMM-yolk was used as an extender. This extender was not significantly better than the DMSO-sucrose-yolk ex- 
TABLE 1.-Fertilization rate of cryopreserved muskellunge spermatozoa using four extenders. Combined data for two prefreezing storage times (means $\pm \mathrm{SD}, N=8$ ) are expressed as percentage of control (fertilization rate of fresh semen). Treatment means along a row without a letter in common are significantly different $(P<0.05)$. Calculations for each extender were made on combined data for both storage times due to a lack of statistical interaction. Data for methanolRinger extender were excluded from calculations of significance.

\begin{tabular}{lcccc}
\hline $\begin{array}{c}\text { Stage and } \\
\text { days postactivation }\end{array}$ & DMSO-sucrose-yolk & & & \\
DMSO-SPMM-yolk & & Glycerol-glucose $^{\mathrm{c}}$ & Methanol-Ringer $^{\mathrm{d}}$ \\
\hline Embryos (4 d) & $37.1 \pm 8.6 \mathrm{y}$ & $47.1 \pm 7.0 \mathrm{z}$ & $30.7 \pm 13.6 \mathrm{y}$ & $34.9 \pm 2.3$ \\
Eyed embryos (12 d) & $35.2 \pm 9.7 \mathrm{zy}$ & $46.6 \pm 10.6 \mathrm{z}$ & $24.7 \pm 15.9 \mathrm{y}$ & $29.9 \pm 20.8$ \\
Hatched embryos (17 d) & $35.1 \pm 9.3 \mathrm{z}$ & $46.2 \pm 10.9 \mathrm{z}$ & $24.4 \pm 15.7 \mathrm{y}$ & $29.9 \pm 20.5$ \\
\hline
\end{tabular}

a Consisted of $10 \%$ dimethyl sulfoxide (DMSO), $0.6 \mathrm{M}$ sucrose, and $10 \%$ egg yolk.

b Consisted of $10 \%$ DMSO in seminal-plasma-mimicking medium (SPMM) and $10 \%$ egg yolk.

${ }^{c}$ Consisted of $20 \%$ glycerol and $0.3 \mathrm{M}$ glucose.

${ }^{\mathrm{d}}$ Consisted of $10 \%$ methanol in modified fish Ringer solution (Rana and McAndrew 1989).

tender when embryo survival was compared at $17 \mathrm{~d}$.

We found significantly $(P<0.05)$ lower fertilizing ability (for all three embryonic stages) of semen stored $5 \mathrm{~h}$ on ice before cryopreservation compared with semen preserved within $1 \mathrm{~h}$ of collection (Table 2). An average decrease in fertilization success was $22-23 \%, 10-12 \%$, and $25-$ $34 \%$ for sperm cryopreserved in DMSO-sucroseyolk, DMSO-SPMM-yolk, and glycerol-glucose extenders, respectively.

Postthaw motility was recorded at $31 \%$ to $47 \%$ in all extenders (Table 3 ). The exception was methanol-Ringer, where few or no motile cells were observed. This extender was not included in statistical analysis. Spermatozoa cryopreserved in DMSO-SPMM-yolk extender had significantly higher VSL and LIN $(P<0.05)$ than those cryopreserved with DMSO-sucrose-yolk and glycerol-glucose extenders, but not DMSO-sucrosebicarbonate-GSH extender (Table 2). However, this last extender was not used in the fertilizing ability trials. Extender type did not significantly

TABLE 2.-Effect of prefreezing storage time on fertilization rate of cryopreserved muskellunge spermatozoa. Combined data for three extenders (means $\pm \mathrm{SD} ; N=$ 12), expressed as percentage of control (fertilization rate of fresh semen), are presented. Treatment means along a row without a letter in common are significantly differen $(P<0.05)$. Calculations for each storage time were made on combined data for three extenders due to a lack of statistical interaction. Data for methanol-Ringer extender were excluded from calculations of significance.

\begin{tabular}{lcc}
\hline $\begin{array}{c}\text { Stage and } \\
\text { days postactivation }\end{array}$ & 1-h storage & 5-h storage \\
\hline Embryos (4 d) & $42.4 \pm 10.7 \mathrm{z}$ & $34.2 \pm 12.0 \mathrm{y}$ \\
Eyed embryos (12 d) & $39.6 \pm 12.7 \mathrm{z}$ & $31.4 \pm 16.4 \mathrm{y}$ \\
Hatched embryos (17 d) & $39.2 \pm 12.5 \mathrm{z}$ & $31.3 \pm 16.5 \mathrm{y}$ \\
\hline
\end{tabular}

affect percentage of motile spermatozoa, VCL, or ALH.

We found that spermatozoa stored for $5 \mathrm{~h}$ before cryopreservation had significantly lower $(P<$ $0.05)$ VCL than those stored only for $1 \mathrm{~h}$ (Table 4). No significant differences were found for VSL and LIN between the two storage times.

Only traces of sperm motility $(<1 \%)$ were detected in 5 out of 10 semen specimens frozen in methanol-Ringer extender, and no motility was detected in the other 5 samples, when CASA was used for motility studies. When motility was recorded at $35 \mathrm{~s}$ postactivation, we found a slight decrease in percentage of motile cells $(1.2+2.0 \%)$ due to an increase in sperm motility in one sample of $6.5 \%$, but this increase was not statistically significant (data not shown). Subjective microscopic observations of sperm motility in a sample of semen also revealed a lack of sperm motility. We recorded only traces of motility $(0.1 \%)$ in one of eight samples. However, we observed a low but significant $(P<0.05)$ sperm activation (mean $=$ $5.3+4.4 \%$ of motile cells) in all five samples tested when the pellets were thawed in egg water. This activation did not occur immediately after thawing; it was about $20-35$ s before motile cells were observed.

\section{Discussion}

Our data on embryo survival of controls were similar to those of rainbow trout Oncorhynchus mykiss under hatchery conditions, where average survival of $90 \%, 80 \%$, and $75 \%$ after fertilization, eyeing, and hatching, respectively, is considered acceptable (Bromage and Cumaranatunga 1988). Fertilization success in our experiment was higher than obtained previously by Lin et al. (1996; 72.9 $\%$ at eyed stage), Moore (1991; 1.3-76.0\%), and Babiak et al. (1995; for northern pike, $69.8 \%$ and 
TABLE 3.-Sperm motility characteristics of cryopreserved muskellunge spermatozoa measured $15-20 \mathrm{~s}$ postactivation in relation to different extenders. Combined data for two prefreezing storage times (means $\pm \mathrm{SD}, N=10$ ) are presented. Extenders are defined in Table 1; VCL = curvilinear velocity, VSL $=$ straight-line velocity, LIN = linearity of movement, ALH = amplitude of lateral load displacement. Treatment means along a row without a letter in common are significantly different $(P<0.05)$. Calculations for each extender were made on combined data for both storage times due to a lack of statistical interaction. Data for methanol-Ringer extender were excluded from calculations of significance.

\begin{tabular}{|c|c|c|c|c|c|}
\hline Variable & $\begin{array}{c}\text { DMSO- } \\
\text { sucrose-yolk }\end{array}$ & $\begin{array}{c}\text { DMSO- } \\
\text { SPMM-yolk }\end{array}$ & Glycerol-glucose & $\begin{array}{c}\text { DMSO-sucrose- } \\
\text { potassium } \\
\text { bicarbonate- } \\
\text { GSH }^{\mathrm{a}}\end{array}$ & Methanol-Ringer \\
\hline Motile cells (\%) & $39.6 \pm 14.2 \mathrm{z}$ & $34.9 \pm 9.5 \mathrm{z}$ & $41.4 \pm 7.8 \mathrm{z}$ & $38.9 \pm 10.3 \mathrm{z}$ & $0.5 \pm 0.7$ \\
\hline $\operatorname{VCL}(\mu \mathrm{m} / \mathrm{s})$ & $317.6 \pm 63.1 \mathrm{z}$ & $302.9 \pm 38.5 \mathrm{z}$ & $282.7 \pm 57.1 \mathrm{z}$ & $335.2 \pm 55.8 \mathrm{z}$ & $282.7 \pm 57.1^{\mathrm{b}}$ \\
\hline $\operatorname{VSL}(\mu \mathrm{m} / \mathrm{s})$ & $60.2 \pm 16.7 y$ & $76.2 \pm 12.1 \mathrm{z}$ & $55.5 \pm 11.7 \mathrm{y}$ & $78.1 \pm 11.8 \mathrm{z}$ & $282.7 \pm 57.1^{\mathrm{b}}$ \\
\hline LIN & $18.8 \pm 4.6 \mathrm{y}$ & $25.6 \pm 5.1 \mathrm{z}$ & $19.9 \pm 5.0 \mathrm{y}$ & $23.6 \pm 4.0 \mathrm{z}$ & $11.8 \pm 6.1^{b}$ \\
\hline $\mathrm{ALH}(\mu \mathrm{m})$ & $5.1 \pm 1.1 \mathrm{z}$ & $4.8 \pm 0.8 \mathrm{z}$ & $4.5 \pm 0.7 \mathrm{z}$ & $5.2 \pm 1.1 \mathrm{z}$ & $5.9 \pm 2.4^{b}$ \\
\hline
\end{tabular}

a Consists of one part DMSO (12.5\% final concentration) mixed with seven parts of medium containing $125 \mathrm{mM}$ sucrose, $100 \mathrm{mM}$ potassium bicarbonate and $6.5 \mathrm{mM}$ reduced glutathione (GSH).

b $N=5$ due to lack of motile cells in 5 of 10 samples.

$67.4 \%$, for eyed stage and hatching, respectively). A similar result for northern pike $(78 \%)$ was obtained by Billard (1978). Based on these reported survival rates, we conclude that our procedures of fresh gamete handling and embryo incubation were appropriate.

Storage of muskellunge semen for $5 \mathrm{~h}$ on ice maintained a high sperm fertilizing ability. However, ability of the semen to be successfully cryopreserved decreased. The phenomenon of decreasing usefulness of stored semen for cryopreservation has been noted in rainbow trout (Stoss 1983). Stoss and Holtz (1983) observed a decrease in fertilizing ability of rainbow trout semen (estimated as eyed-stage embryos) from $81 \%$ for semen stored 20 min before freezing to $73 \%$ for semen stored for $305 \mathrm{~min}$. Similar observations were also recently made for rainbow trout by Weismann et al. (1995). On the other hand, Rana et al. (1990)

TABLE 4.-Effect of prefreezing storage time on sperm motility characteristics of cryopreserved muskellunge spermatozoa. Combined data for four extenders (means \pm $\mathrm{SD}, N=20$ ), are presented. Treatment means along a row without a letter in common are significantly different $(P$ $<0.05$ ). Calculations for each storage time were made on combined data for three extenders due to a lack of statistical interaction. Data for methanol-Ringer extender were excluded from calculations of significance. Variables are defined in Table 3.

\begin{tabular}{lcc}
\hline \multicolumn{1}{c}{ Variables } & 1-h storage & 5-h storage \\
\hline Motile cells $(\%)$ & $38.1 \pm 10.6 \mathrm{z}$ & $40.3 \pm 11.0 \mathrm{z}$ \\
VCL $(\mu \mathrm{m} / \mathrm{s})$ & $317.9 \pm 63.1 \mathrm{z}$ & $302.0 \pm 28.5 \mathrm{y}$ \\
VSL $(\mu \mathrm{m} / \mathrm{s})$ & $72.4 \pm 16.1 \mathrm{z}$ & $62.6 \pm 14.8 \mathrm{z}$ \\
LIN & $23.2 \pm 5.1 \mathrm{z}$ & $20.8 \pm 5.3 \mathrm{z}$ \\
ALH $(\mu \mathrm{m})$ & $5.0 \pm 1.1 \mathrm{z}$ & $4.8 \pm 0.7 \mathrm{z}$ \\
\hline
\end{tabular}

found that prefreezing storage of up to $6 \mathrm{~d}$ of milt of Nile tilapia Oreochromis niloticus had no significant effect on sperm fertilizing ability. Based on our fertility and motility studies, time between collection and cryopreservation of muskellunge semen must be minimized. Our results indicate that VCL, but not percentage of motile cells, VSL, LIN, or ALH, appeared to predict a negative effect of prefreezing storage on fertilizing ability of muskellunge spermatozoa.

This study indicates that all tested extenders preserve sperm fertilizing ability to some degree but that the DMSO-SPMM-yolk extender, developed by Babiak et al. (1995), seems to be the best available for cryopreservation of both northern pike and muskellunge semen compared with previous results with esocid fish (De Montalembert et al. 1978; Stein and Bayrle 1978; Koldras and Moczarski 1983; Moore 1991). We observed lower variability in fertilization success (coefficient of variation, $\mathrm{CV}=100 \times \mathrm{SD} /$ mean $=11-25 \%$ ) when using DMSO-SPMM-yolk extender with muskellunge than was found with northern pike $(\mathrm{CV}=$ 41\%; Babiak et al. 1995). This conclusion is based on fertility studies, whereas results of CASA were highly variable, possibly due to the effect of egg factors on motility (see below). Nevertheless, it should be noted that VSL and LIN values of the DMSO-SPMM-yolk extender were significantly higher than those of the two other extenders used for fertility studies. This suggests that VSL and LIN may be related to sperm fertilizing ability.

We recorded no motility or only traces of motile cells (below 1\%) in semen samples cryopreserved in methanol when observed by CASA up to $35 \mathrm{~s}$ 
postactivation. There seemed to be no relation between this motility and sperm fertility. For example, one sample with $0 \%$ motile cells had $67.9 \%$ fertilization success. We did not observe, using microscopic observation, any increase in sperm motility at a postactivation time longer than $35 \mathrm{~s}$. Therefore, it seems unlikely that spermatozoa cryopreserved with methanol could be activated at longer postactivation times.

We considered three possible explanations for the phenomenon of cryopreserved sperm with little or no motility showing fertilization success: (1) sperm motility was suppressed by conditions (pressure?) of the sperm analysis chamber as suggested by Rana et al. (1990), (2) sperm motility was activated by egg factors, or (3) eggs were fertilized by immotile spermatozoa. We rejected the first explanation because we did not observe any motility in sperm drops, but we supported the second hypothesis in the present study. Tris- $\mathrm{HCl}$ buffer was not effective in supporting sperm motility alone but was effective after it was incubated with eggs for $5 \mathrm{~min}$. This strongly suggests that factors in eggs or ovarian fluid can stimulate sperm motility. Consequently, it is unlikely that immotile sperm could fertilize eggs.

A similar phenomenon of good fertility of semen frozen using methanol-Ringer extender with no postthaw motility was observed by Rana et al. (1990) in specimens of Nile tilapia semen (those with prolonged storage before freezing). These authors offered three speculative explanations, including the presence of motile cells out of focus on the microscope, retardation of sperm motility caused by the coverslip, or activation of sperm motility by ovarian fluid. Our data indicate that egg factors may be involved in activation of spermatozoa and that this led to fertilization. During recent years, sperm activating substances from teleost fish eggs have been characterized (Morisawa et al. 1992; Yanagimachi et al. 1992; Pillai et al. 1993, 1994; Oda et al. 1995). These factors originated from eggs (micropyle area) rather than from ovarian fluid and are proteins or peptides (Pillai et al. 1993; Oda et al. 1995). Our data support the idea that fish spermatozoa activation or modulation of activation by egg factors may be a universal phenomenon (Yanagimachi et al. 1992). However, localization (eggs or ovarian fluid) identification, and characterization of sperm activation factors from muskellunge ova are necessary to support this speculation..

\section{Acknowledgments}

We thank Frederick S. Ruland of the Academic Computing Services of the Ohio State University for statistical consultation. We appreciate the helpful cooperation of Richard Day, Frank Kapler, and Bruce Bartens from the Ohio Department of Natural Resources in sampling gametes. Thanks to Patricia M. Laskowski for commenting on the manuscript. This work was funded by Federal Aid in Sport Fish Restoration, project F-69-P (Fish Management in Ohio), which is administered jointly by the U.S. Fish and Wildlife Service and the Ohio Division of Wildlife. Salaries were partly provided by the state and federal funds appropriated to the Ohio Agriculture and Development Center.

\section{References}

Babiak, I., J. Glogowski, M. J. Luczynski, D. Kucharczyk, and M. Luczynski. 1995. Cryopreservation of the milt of the northern pike (Esox lucius L.). Journal of Fish Biology 46:819-828.

Bardega, R., and M. Luczynski. 1990. Experimental hatchery and larvae rearing unit. Acta Academiae Agriculturae ac Technicae Olstenensis Protectio Aquarum et Piscatoria 18:87-93.

Billard, R. 1978. Changes in structure and fertilizing ability of marine and freshwater fish spermatozoa diluted in media of various salinities. Aquaculture 14:187-198.

Bromage, N., and R. Cumaranatunga. 1988. Egg production in the rainbow trout. Pages 63-138 in F. Muir and J. Roberts, editors. Recent advances in aquaculture. Croom Helm, London.

Ciereszko, A., and K. Dabrowski. 1993. Estimation of sperm concentration of rainbow trout, whitefish, and yellow perch spermatozoa using a spectrophotometric technique. Aquaculture 109:367-373.

Ciereszko, A., and K. Dabrowski. 1996. Effect of a sucrose-DMSO extender supplemented with pentoxifylline or blood plasma on fertilizing ability of cryopreserved rainbow trout spermatozoa. Progressive Fish-Culturist 58:143-145.

Ciereszko, A., L. Ramseyer, and K. Dabrowski. 1993. Cryopreservation of yellow perch semen. Progressive Fish-Culturist 55:261-264.

Ciereszko, A., G. P. Toth, S. A. Christ, and K. Dabrowski. 1996. Effect of cryopreservation and theophylline on motility characteristics of lake sturgeon (Acipenser fulvescens) spermatozoa. Theriogenology 45:665-672.

De Montalembert, G., C. Bry, and R. Billard. 1978. Control of reproduction in northern pike. Pages 217-225 in R. L. Kendall, editor. Selected coolwater fishes of North America. American Fisheries Society, Special Publication 11, Bethesda, Maryland.

Erdhal, A. W., and E. F. Graham. 1987. Fertility of teleost semen as affected by dilution and storage in 
a seminal plasma-mimicking medium. Aquaculture 60:311-321.

Holtz, W. 1993. Cryopreservation of rainbow trout (Oncorhynchus mykiss) sperm: practical recommendations. Aquaculture 110:97-100.

Koldras, M., and M. Moczarski. 1983. Properties of pike Esox lucius L. milt and its cryopreservation. Polskie Archiwum Hydrobiologii 30:69-78.

Lin, F., A. Ciereszko, and K. Dabrowski. 1996. Sperm production and cryopreservation in muskellunge after carp pituitary extract and hCG injection. Progressive Fish-Culturist 58:32-37.

Lin, F., and K. Dabrowski. 1996. Effects of sperm irradiation and heat shock on induction of gynogenesis in muskellunge (Esox masquinongy). Canadian Journal of Fisheries and Aquatic Sciences 53: 20672075.

Moore, A. A. 1991. Refrigerated storage and cryopreservation of walleye and muskellunge semen. Iowa Department of Natural Resources, Fish and Wildlife Division, Technical Bulletin 4, Des Moines.

Morisawa, M., S. Tanimoto, and H. Ohtake. 1992. Characterization and partial purification of sperm-activating substance from eggs of the herring, Clupea pallasi. Journal of Experimental Zoology 264:225230.

Mounib, M. S. 1978. Cryogenic preservation of fish and mammalian spermatozoa. Journal of Reproduction and Fertility 53:13-18.

Oda, S., Y. Igarashi, H. Ohtake, K. Sakai, N. Shimizu, and M. Morisawa. 1995. Sperm-activating proteins from unfertilized eggs of the Pacific herring, Clupea pallasi. Development, Growth and Differentiation 37:257-261.

Owen, D. H., and D. F. Katz. 1993. Sampling factors influencing accuracy of sperm kinematic analysis. Journal of Andrology 14:210-221.

Piironen, J. 1995. Composition and cryopreservation of sperm from some Finnish freshwater teleost fish. Finnish Fisheries Research 15:65-86.

Piironen, J., and H. Hyvärinen. 1983. Cryopreservation of spermatozoa of the whitefish Coregonus mukusun Pallas. Journal of Fish Biology 22:159-163.

Pillai, M. C., T. S. Shields, R. Yanagimachi, and G. N. Cherr. 1993. Isolation and partial characterization of the sperm motility initiation factor from eggs of the Pacific herring, Clupea pallasi. Journal of Experimental Zoology 265:336-342.

Pillai, M. C., R. Yanagimachi, and G. N. Cherr. 1994. In vivo and in vitro initiation of sperm motility using fresh and cryopreserved gametes from the $\mathrm{Pa}$ cific herring, Clupea pallasi. Journal of Experimental Zoology 269:62-68.
Rana, K. 1995. Cryopreservation of aquatic gametes and embryos: recent advances and applications. Pages 85-89 in F. W. Goetz and P. Thomas, editors. Proceedings of the fifth international symposium on the reproductive physiology of fish. University of Texas, Fish Symposium 95, Austin.

Rana, K. J., and B. J. McAndrew. 1989. The viability of cryopreserved tilapia spermatozoa. Aquaculture 76:335-345.

Rana, K. J., R. M. Muiruri, B. J. McAndrew, and A. Gilmour. 1990. The influence of diluents, equilibration time and pre-freezing storage time on the viability of cryopreserved Oreochromis niloticus (L.) spermatozoa. Aquaculture and Fisheries Management 21:25-30.

SAS Institute. 1989. SAS/STAT user's guide, version 6, 4 edition, volume 2. SAS Institute, Cary, North Carolina.

Stein, H., and H. Bayrle. 1978. Cryopreservation of the sperm of some freshwater teleosts. Annales de Biologie animale, Biochimie, Biophysique 18:10731076.

Stoss, J. 1983. Fish gamete preservation and spermatozoan physiology. Pages 305-350 in W. J. Hoar, D. J. Randall, and E. M. Donaldson, editors. Fish Physiology, volume 9, part B. Academic Press, San Diego, California.

Stoss, J., and W. Holtz. 1983. Cryopreservation of rainbow trout (Salmo gairdneri) sperm. III. Effects of proteins in the diluent, sperm from different males and interval between collection and freezing. Aquaculture 31:275-282.

Toth, G. P., S. A. Christ, H. M. McCarthy, J. A. Torsella, and M. K. Smith. 1995. Computer-assisted motion analysis of sperm from common carp, Cyprinus carpio. Journal of Fish Biology 47:986-1003.

Toth, G. P., A. Ciereszko, S. A. Christ, and K. Dabrowski. 1997. Objective analysis of sperm motility in the lake sturgeon, Acipenser fulvescens: activation and inhibition conditions. Aquaculture 154:337348.

Weismann, T., F. Lahsteiner, and R. A. Patzner. 1995. Cryopreservation of semen of salmonid fishes and its adaptation for practical application. Pages 9092 in F. W. Goetz and P. Thomas, editors. Proceedings of the fifth international symposium on the reproductive physiology of fish. University of Texas, Fish Symposium 95, Austin.

Yanagimachi, R., G. N. Cherr, M. C. Pillai, and J. D. Baldwin. 1992. Factors controlling sperm entry into the micropyle of salmonid and herring eggs. Development, Growth and Differentiation 34:447461. 